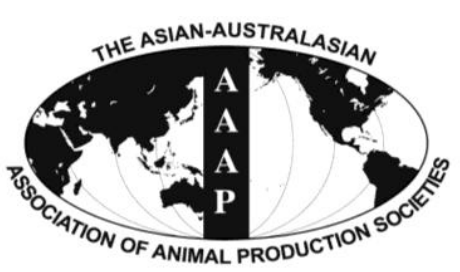

Open Access

Asian Australas. J. Anim. Sci.

Vol. 28, No. 2 : 188-199 February 2015

http://dx.doi.org/10.5713/ajas.14.0325

www.ajas.info

pISSN 1011-2367 elSSN 1976-5517

\title{
Effect of Tannin and Species Variation on In vitro Digestibility, Gas, and Methane Production of Tropical Browse Plants
}

\author{
B. S. Gemeda* and A. Hassen \\ Department of Animal and wildlife Sciences, University of Pretoria, Hatfield, Pretoria 0028, South Africa
}

\begin{abstract}
Nineteen tanniferous browse plants were collected from South Africa to investigate their digestibility, gas production (GP) characteristics and methane production. Fresh samples were collected, dried in forced oven, and ground and analyzed for nutrient composition. In vitro GP and in vitro organic matter digestibility (IVOMD) were determined using rumen fluid collected, strained and anaerobically prepared. A semi- automated system was used to measure GP by incubating the sample in a shaking incubator at $39^{\circ} \mathrm{C}$. There was significant $(\mathrm{p}<0.05)$ variation in chemical composition of studied browses. Crude protein $(\mathrm{CP})$ content of the species ranged from 86.9 to $305.0 \mathrm{~g} / \mathrm{kg}$ dry matter (DM). The neutral detergent fiber (NDF) ranged from 292.8 to $517.5 \mathrm{~g} / \mathrm{kg}$ DM while acid detergent fiber (ADF) ranged from 273.3 to $495.1 \mathrm{~g} / \mathrm{kg}$ DM. The ash, ether extract, non-fibrous carbohydrate, neutral detergent insoluble nitrogen, and acid detergent insoluble nitrogen and $\mathrm{CP}$ were negatively correlated with methane production. Methane production was positively correlated with NDF, ADF, cellulose and hemi-cellulose. Tannin decreased GP, IVOMD, total volatile fatty acid and methane production. The observed low methanogenic potential and substantial ammonia generation of some of the browses might be potentially useful as rumen manipulating agents. However, a systematic evaluation is needed to determine optimum levels of supplementation in a mixed diet in order to attain a maximal depressing effect on enteric $\mathrm{CH}_{4}$ production with a minimal detrimental effect on rumen fermentation of poor quality roughage based diet. (Key Words: Digestibility, Gas Production, Methane, Ammonia, Volatile Fatty Acids)
\end{abstract}

\section{INTRODUCTION}

Enteric methane is a greenhouse gas that causes significant loses of energy in ruminants and estimated to represent globally 2,079 and 2,344 $\mathrm{Mt} \mathrm{CO}_{2}$-eq/year for 2010 and 2020, respectively (Hristov et al., 2013). Enteric methane is produced by methanogenic archaea and symbiotic associations of protozoa to dispose metabolic hydrogen during feed fermentation (Leng, 2008). So, in targeting methane reduction it is crucial to develop a strategy that decrease methane producing micro-biota activities and proliferation without limiting rumen function.

Recently there are numerous reports that have shown the reduction of enteric methane due to inclusion of tannin rich browses because the tannins have anti-methanogenic

\footnotetext{
* Corresponding Author: Belete Shenkute Gemeda. Tel: +27-1242-03-273, Fax: +27-12-42-03-290, E-mail: beletegemeda@ gmail.com
}

Submitted May 6, 2014; Revised Jul. 20, 2014; Accepted Aug. 23, 2014 activity, either by direct inhibition of methanogens or indirectly through inhibition of protozoa (Animut et al., 2008; Hristov et al., 2013). Tannins are polyphenolic compounds which bind to protein and can be used as chemical additives for protecting and decreasing ruminal fermentation of proteins in ruminant feeds (Makkar, 2003). They are complex polymers with various linkages and bonds that vary among browse species and within parts of plants (Makkar, 2003; Patra and Saxena, 2011). This contributes to differences in degree of polymerization and chemical structures that further contributes to the differing biological properties (Patra and Saxena, 2011).

The huge diversity in tannin structures may explain their vast variable effects on methanogenesis and rumen function depending on source, type and level of tannin (Mueller-Harvey, 2006; Patra et al., 2011). Apart from variation among plants and tannins, different ruminant species also vary in their responses to tannin. Tannins from different plants exhibit variation in their effects at the same concentration as evidenced by difference in magnitudes of 
gas production (GP) and digestibility (Makkar, 2003; Guglielmelli et al, 2011). This indicates that tannin from different plants might show different response in digestibility and methane production. Interestingly, most tropical browses contain reasonably high nitrogen and low fiber content and thus can be considered as supplemental feed for poor quality roughages. However, the net improvement in digestibility is much influenced by the type and the level of phenolic compounds under tropical condition where supplementation of nitrogen is critical. Characterization of the existing tropical browse resources for fermentation and methane production potential is crucial. Moreover, their strategic inclusion to poor quality feed to optimize their utilization in ruminants feeding can be regarded as a way forward (Beauchemin et al., 2008). This in vitro study was aimed to investigate the effect of tannin rich browse on gas and $\mathrm{CH}_{4}$ production, organic matter degradability, ammonia and volatile fatty acid (VFA) production, as well as studying the correlation of in vitro organic matter digestibility (IVOMD) and $\mathrm{CH}_{4}$ with chemical and phenolic composition by incubating the samples with and without poly-ethylene glycol (PEG) (molecular weight, 6000).

\section{MATERIALS AND METHODS}

\section{Sample collection, preparation and chemical analysis}

Samples of nineteen tannin rich browse plants were collected from Gauteng province of South Africa in a period of summer rainy season (December 2011 through Feb 2012). The area is located at about $25^{\circ} 44^{\prime} 30^{\prime \prime} \mathrm{S}, 28^{\circ} 15^{\prime} 30^{\prime \prime} \mathrm{E}$, at the elevation of about 1,370 meters above sea level. It has two distinctive seasons: a dry season (March through September) and rainy season (October through February) with warm and humid condition in summer while winter is dry, cold and sunny. This is a summer rainfall area with a mean precipitation of $674 \mathrm{~mm}$ and an average annual temperature of $17.3^{\circ} \mathrm{C}$. The browses were harvested at the same time when they were at the same maturity stage; almost early vegetative stage. Fresh foliages (leaves and stems $<3 \mathrm{~mm}$ diameter) were harvested from at least five randomly selected and tagged representative plants of each species. Samples from each species (up to $200 \mathrm{~g}$ ) were dried at $55^{\circ} \mathrm{C}$ for $48 \mathrm{~h}$ and ground to pass a $1-\mathrm{mm}$ screen for subsequent chemical and in vitro analyses.

Feed samples were analyzed for dry matter (DM) and total ash using the method of AOAC (2002). Fat content was determined using ether extraction in the Tecator Soxtec (HT6) system (AOAC, 2002). The neutral detergent fiber (NDF), acid detergent fiber (ADF) and acid detergent lignin (ADL) contents were determined using an ANKOM 200/220 Fiber Analyzer (ANKOM Technology, Fairport, NY, USA) according to the methodology supplied by the company, which is based on the methods described by Van Soest et al. (1991). Sodium sulphite and heat-stable amylase were used in analysis of NDF. Nitrogen was analyzed by method described in AOAC (2002) on a Leco FP-428 Nitrogen and Protein analyzer (Leco Corporation, St. Joseph, MI, USA), and crude protein (CP) was calculated as $\mathrm{N} \times 6.25$. The $\mathrm{N}$ content of NDF and ADF (i.e., neutral detergent insoluble nitrogen, NDIN; acid detergent insoluble nitrogen, ADIN) were determined by the $\mathrm{CP}$ method referenced above and expressed exclusive of residual ash.

Determinations of total phenols (TP), total tannins (TT) and condensed tannins (CT) were done following procedure described by Makkar (2003). Condensed tannins were determined by the butanol-HCl-iron method (Porter et al., 1985). The hydrolysable tannins (HT) were estimated as the difference between TT and CT (Singh et al., 2005). Total phenols and tannins were expressed as tannic acid equivalent and CTs as leucocyanidin equivalent.

\section{Measurement of gas production and in vitro digestible organic matter}

Collection of rumen fluid and preparation of buffer solution: The rumen fluid was collected from three rumen cannulated South African mutton Merino sheep fed ad libtum of alfalfa hay before the morning feeding. The hay contains $175 \mathrm{~g} / \mathrm{kg} \mathrm{DM}$ of CP, $465 \mathrm{~g} / \mathrm{kg} \mathrm{DM}$ of NDF and 8 $\mathrm{MJ} / \mathrm{kg} \mathrm{DM}$ of metabolizable energy (ME).

It was prepared and maintained an-aerobically being purged with $\mathrm{CO}_{2}$ to maintain anaerobic conditions in the laboratory (Grant and Mertens, 1992). After blending, the rumen fluid was transferred to a large glass beaker inside a $39^{\circ} \mathrm{C}$ water bath being continuously purged with $\mathrm{CO}_{2}$ and continuously stirred as recommended by Goering and Van Soest (1970). The buffer solution, macro mineral solution and micro mineral solution were prepared in large volumes and utilized as needed as described in Goering and Van Soest (1970).

Measurement of gas production and in vitro digestible organic matter: Gas production was determined as described by Theodorou et al. (1994). Approximately 400 $\mathrm{mg}$ of respective browse feed sample with or without 400 $\mathrm{mg}$ of PEG (molecular weight, 6000, analytical grade sigma-aldrich) was weighed into $120 \mathrm{~mL}$ serum bottle. Then $40 \mathrm{~mL}$ of rumen fluid+medium was added under a stream of $\mathrm{CO}_{2}$ to each serum bottles after which closed with rubber stoppers and crimp seal caps. Needle was inserted through rubber stopper of each serum bottles for about 5 seconds to release small amount of gas that might have built up and create starting point for incubation. All serum bottles were returned to the incubator and the rotary shaker was turned on $120 \mathrm{rpm}$. Gas pressure was taken at 2, 8, 12, 24, $32,48,54$, and 72 h. Four consecutive incubation runs of 72 
$\mathrm{h}$ were carried out with two bottles per substrate. To quantify the GP derived from the culture medium and the ruminal inoculums two blank were incubated without substrate in each run and were used to correct GP from inoculum fermentation within incubation runs. Supernatants were taken after $72 \mathrm{hrs}$ of incubation, immediately pipetted and stored at $-20^{\circ} \mathrm{C}$ until analyzed for ammonia $\mathrm{N}$ (McDonald et al., 1960) and VFAs (Ottenstein and Bartley, 1971).

The IVOMD content was determined according to the method of Tilley and Terry (1963), as modified by Engels and Van der Merwe (1967). The method involved two digestion phases. During the first digestion phase, feed samples (200 $\mathrm{mg})$ were incubated in triplicate under anaerobic conditions with rumen liquor for $48 \mathrm{~h}$ at $39^{\circ} \mathrm{C}$, with the inclusion of blanks and standards in every batch of incubation. This was followed by an acid pepsin digestion phase for $48 \mathrm{~h}$ at $39^{\circ} \mathrm{C}$, under anaerobic conditions Following the incubation for $96 \mathrm{~h}$, the residual plant materials were collected and oven-dried at $105^{\circ} \mathrm{C}$ for $12 \mathrm{~h}$. Ash contents were determined by combustion at $550^{\circ} \mathrm{C}$ for $2 \mathrm{~h}$ (Engels and Van der Merwe, 1967).

\section{Methane measurements}

Methane production was measured separately from duplicate bottles incubated for each browse samples at 2, 12, 24 , and $48 \mathrm{~h}$. The methane concentration was determined using a gas chromatography (SRI 8610C gas chromatograph (GC) BTU Gas Analyzer GC System, Bad Honnef, Germany) equipped with a solenoid column packed with silica gel and a flame ionization detector. Gas produced at each sampling time from each species was recorded and gas samples were taken using a Hamilton syringe. The sampled gas was injected manually (pull and push method of sample injection) into a GC, which was already calibrated with standard $\mathrm{CH}_{4}$ and $\mathrm{CO}_{2}$. Four consecutive incubation runs of $48 \mathrm{~h}$ were carried out with two bottles per substrate. Duplicate bottles without substrate were also included in each run as blanks of inoculum to correct methane and GP from inoculum fermentation within incubation runs. The measured methane concentration was related to the respective total gas volume measured in order to estimate its concentration (Tavendale et al., 2005). The $\mathrm{CH}_{4}$ gas volume was converted to energy and mass values using the conversion factors $9.45 \mathrm{kcal} / \mathrm{L}$ and $0.716 \mathrm{~g} / \mathrm{L}$ respectively (Santoso et al., 2007).

\section{Calculations and statistical analysis}

Metabolizable energy (MJ/kg DM) was estimated according to Menke and Steingass (1988) as:

$\mathrm{ME}(\mathrm{MJ} / \mathrm{kg} \mathrm{DM})$

$=2.20+0.136 \mathrm{IVGP}_{24}(\mathrm{~mL} / 0.5 \mathrm{~g} \mathrm{DM})+0.057 \mathrm{CP}(\% \mathrm{DM})$ where IVGP $_{24}$, volume of gas produced during $24 \mathrm{~h}$.

Rate and extent of GP was determined for each feed by fitting GP data to the non-linear equation: $y=a+b\left(1-\mathrm{e}^{-c t}\right)$ (Ørskov and McDonald, 1979), where y is the volume of GP at time $\mathrm{t}(\mathrm{mL})$; $\mathrm{a}$ is soluble component, $\mathrm{b}$ is the GP from the insoluble but slowly fermentable/degradable fraction $(\mathrm{mL})$; $\mathrm{c}$ is the rate of GP from insoluble fraction per hour.

Methane concentration was determined as:

Methane (mL)

$=$ Total gas produced $(\mathrm{mL}) \times \%$ methane in the sample

Methane increase (\%)

$=\left\{\left[\mathrm{CH}_{4}\right.\right.$ with $\mathrm{PEG}$ addition $(\mathrm{mL})$

$-\mathrm{CH}_{4}$ without $\mathrm{PEG}$ addition $\left.\left.(\mathrm{mL})\right] \times 100\right\}$

$/\left[\mathrm{CH}_{4}\right.$ with $\mathrm{PEG}$ addition $\left.(\mathrm{mL})\right]$

Data were statistically analyzed using proc general linear model option of SAS (2004), considering each incubation run as a block. The average of the two bottles was considered as data from the experimental unit. The differences among means were determined using Tukey test. While statistical differences between PEG(+) and PEG(-) were presented in the text. Pearson correlation (PROC CORR, SAS 2004) analysis was used to determine significant relationships among the different parameters used in the study.

\section{RESULTS}

\section{The composition of browses}

The leaves of studied browses species differed significantly $(\mathrm{p}<0.05)$ in terms of their chemical compositions (Table 1). The CP, NDIN, and ADIN values were ranged between 86.9 to $305,5.4$ to 41.4 , and 11.8 to $48.1 \mathrm{~g} / \mathrm{kg}$ DM, respectively. The highest CP value was recorded for Leucaena leucocephala, while the lowest value was recorded for Rhus lancea and Euphorbia tirucalli. The highest NDIN content was found for Melia azedarach while Kirkia acuminata had the highest value of ADIN. The lowest value of NDIN and ADIN was recorded in Euphorbia tirucalli. The NDF (g/kg DM) values ranged from 292.8 to $522.4 \mathrm{~g} / \mathrm{kg}$ DM. The highest value was recorded in Quercus rubica while the lowest value was recorded in Morus alba. Whereas ADF (g/kg DM) value ranged from 271.6 in Kirkia acuminata to 485.1 in Peltrophorum africanum. The highest value of lignin was recorded for Olea africanum whereas Euphorbia tirucalli contains the lowest value.

The phenolic compositions of the browse species were significantly different $(\mathrm{p}<0.05) \quad($ Table 2$)$. The TP concentration ranged between 32.4 to $209.1 \mathrm{~g} / \mathrm{kg}$ DM. The TT concentration of the browses ranged between 13.4 to 
Table 1. Chemical composition of browse plants (mean) used in the study $(\mathrm{n}=3)$

\begin{tabular}{|c|c|c|c|c|c|c|c|c|c|}
\hline \multirow{2}{*}{ Scientific name } & \multicolumn{9}{|c|}{ Chemical components (g/kg DM) } \\
\hline & Ash & $\mathrm{OM}$ & $\mathrm{CP}$ & NDIN & ADIN & $\mathrm{ADF}$ & $\mathrm{NDF}$ & ADL & $\mathrm{EE}$ \\
\hline Acacia nilotica & $90.8^{\mathrm{g}}$ & $836.8^{\mathrm{h}}$ & $153.9^{\mathrm{k}}$ & $23.9^{f}$ & $22.8^{\mathrm{h}}$ & $410.3^{\mathrm{d}}$ & $517.5^{\mathrm{a}}$ & $153.2^{\mathrm{d}}$ & $26.3^{\mathrm{ijk}}$ \\
\hline Acacia sieberriana woodii & $72.4^{\mathrm{j}}$ & $804.3^{\mathrm{k}}$ & $285.4^{\mathrm{c}}$ & $33.4^{\mathrm{c}}$ & $32.2^{\mathrm{c}}$ & $364.7^{\mathrm{fg}}$ & $425.8^{\mathrm{d}}$ & $174.3^{\mathrm{c}}$ & $41.4^{\mathrm{b}}$ \\
\hline Combretum microphyllum & $81.3^{\mathrm{i}}$ & $840.6^{\mathrm{gh}}$ & $165.1^{\mathrm{j}}$ & $30.0^{\mathrm{e}}$ & $26.0^{\mathrm{f}}$ & $437.8^{\mathrm{c}}$ & $498.2^{\mathrm{b}}$ & $88.2^{\mathrm{j}}$ & $26.2^{\mathrm{jk}}$ \\
\hline Combretum molle & $62.7^{1}$ & $847.8^{\mathrm{f}}$ & $130.8^{1}$ & $19.4^{\mathrm{k}}$ & $17.8^{1}$ & $430.5^{\mathrm{c}}$ & $498.6^{\mathrm{b}}$ & $67.8^{1}$ & $26.7^{\text {hij }}$ \\
\hline Euphorbia tirucalli & $133.3 \mathrm{a}$ & $767.9^{\circ}$ & $87.8^{\mathrm{r}}$ & $11.8^{\mathrm{m}}$ & $5.4^{\circ}$ & $367.4^{\mathrm{f}}$ & $377.9^{\mathrm{f}}$ & $66.1^{1}$ & $28.1^{\mathrm{fgh}}$ \\
\hline Ficus religiosa & $131.5 b$ & $797.2^{1}$ & $126.6^{\mathrm{n}}$ & $19.2^{\mathrm{k}}$ & $19.4^{\mathrm{jk}}$ & $483.2^{\mathrm{b}}$ & $496.3^{\mathrm{b}}$ & $108.1^{\mathrm{g}}$ & $18.6^{\mathrm{m}}$ \\
\hline Ficus thronniggi & $120.5 \mathrm{c}$ & $781.6^{\mathrm{n}}$ & $277.8^{\mathrm{d}}$ & $23.8^{\mathrm{h}}$ & $15.1^{\mathrm{m}}$ & $336.9^{\mathrm{i}}$ & $415.6^{\mathrm{d}}$ & $155.1^{\mathrm{d}}$ & $29.4^{\mathrm{ef}}$ \\
\hline Kirkia acuminata & $50.7^{\mathrm{q}}$ & $877.1^{\mathrm{d}}$ & $129.3^{\mathrm{m}}$ & $39.1^{\mathrm{b}}$ & $41.2^{\mathrm{a}}$ & $271.6^{\mathrm{k}}$ & $317.8^{\mathrm{h}}$ & $118.7^{\mathrm{f}}$ & $24.8^{\mathrm{kl}}$ \\
\hline Kirkia willmsii & $65.5^{\mathrm{k}}$ & $874.4^{\mathrm{d}}$ & $103.2^{\mathrm{p}}$ & $22.0^{\mathrm{i}}$ & $20.4^{\mathrm{i}}$ & $356.3^{\mathrm{g}}$ & $370.9^{f}$ & $79.6^{\mathrm{k}}$ & $30.6^{\mathrm{e}}$ \\
\hline Lespendeza cuneata & $58.0^{\mathrm{p}}$ & $885.8^{\mathrm{c}}$ & $214.8^{\mathrm{f}}$ & $23.0^{\mathrm{h}}$ & $19.8^{\mathrm{ij}}$ & $411.1^{\mathrm{d}}$ & $418.2^{\mathrm{d}}$ & $100.4^{\mathrm{h}}$ & $26.1^{\mathrm{jk}}$ \\
\hline Leucaena leucocephala & $86.6^{\mathrm{h}}$ & $827.4^{\mathrm{i}}$ & $305.0^{\mathrm{a}}$ & $39.3^{\mathrm{b}}$ & $32.1^{\mathrm{C}}$ & $382.3^{\mathrm{e}}$ & $443.4^{\mathrm{c}}$ & $89.3^{\mathrm{j}}$ & $29.2^{\text {efg }}$ \\
\hline Melia azedarach & $112.7^{\mathrm{d}}$ & $821.6^{\mathrm{j}}$ & $298.7^{\mathrm{b}}$ & $48.1^{\mathrm{a}}$ & $39.4^{\mathrm{b}}$ & $322.9^{j}$ & $375.4^{\mathrm{f}}$ & $95.0^{\mathrm{i}}$ & $30.1^{\mathrm{e}}$ \\
\hline Morus alba & $120.4 \mathrm{c}$ & $788.7^{\mathrm{m}}$ & $169.7^{\mathrm{i}}$ & $28.2^{\mathrm{f}}$ & $22.9^{\mathrm{h}}$ & $273.3^{\mathrm{k}}$ & $292.8^{\mathrm{j}}$ & $91.7^{\mathrm{ij}}$ & $40.3^{\mathrm{b}}$ \\
\hline Olea europaea & $59.1^{0}$ & $907.7^{\mathrm{a}}$ & $93.0^{\mathrm{q}}$ & $23.6^{\mathrm{h}}$ & $18.7^{\mathrm{k}}$ & $346.7^{\mathrm{h}}$ & $378.6^{\mathrm{f}}$ & $221.2^{\mathrm{b}}$ & $27.8^{\mathrm{ghi}}$ \\
\hline Olea africanum & $61.7^{\mathrm{m}}$ & $907.2^{\mathrm{a}}$ & $111.9^{\circ}$ & $30.2^{\mathrm{e}}$ & $26.4^{\mathrm{f}}$ & $389.3^{\mathrm{e}}$ & $397.5^{\mathrm{e}}$ & $230.9^{\mathrm{a}}$ & $24.3^{1}$ \\
\hline Peltrophorum africanum & $60.1^{\mathrm{n}}$ & $865.4^{\mathrm{e}}$ & $171.7^{\mathrm{h}}$ & $30.1^{\mathrm{e}}$ & $24.2^{\mathrm{g}}$ & $485.1^{\mathrm{a}}$ & $518.7^{\mathrm{a}}$ & $142.9^{\mathrm{e}}$ & $44.4^{\mathrm{a}}$ \\
\hline Quercus rubica & $60.3^{\mathrm{n}}$ & $892.5^{\mathrm{b}}$ & $178.5^{\mathrm{g}}$ & $37.7^{\mathrm{c}}$ & $28.0^{\mathrm{d}}$ & $418.1^{\mathrm{d}}$ & $522.4^{\mathrm{a}}$ & $124.9^{\mathrm{f}}$ & $35.9^{\mathrm{c}}$ \\
\hline Rhus lancea & $105.1 \mathrm{e}$ & $845.3^{\mathrm{fg}}$ & $86.9^{r}$ & $15.3^{1}$ & $14.1^{\mathrm{n}}$ & $390.6^{\mathrm{e}}$ & $424.5^{\mathrm{d}}$ & $78.7^{\mathrm{k}}$ & $32.1^{\mathrm{d}}$ \\
\hline Ziziphus mucronta & $96.9^{f}$ & $840.4^{\mathrm{gh}}$ & $243.3^{\mathrm{e}}$ & $33.1^{\mathrm{d}}$ & $27.2^{\mathrm{e}}$ & $248.3^{1}$ & $339.2^{\mathrm{g}}$ & $101.4^{\mathrm{h}}$ & $17.6^{\mathrm{m}}$ \\
\hline SEM & 0.303 & 1.83 & 0.429 & 0.266 & 0.253 & 3.23 & 3.63 & 1.80 & 0.50 \\
\hline $\mathrm{p}$ value & $<0.001$ & $<0.001$ & $<0.001$ & $<0.001$ & $<0.001$ & $<0.001$ & $<0.001$ & $<0.001$ & $<0.001$ \\
\hline
\end{tabular}

Dm, dry matter; OM, organic matter; CP, crude protein; NDIN, neutral detergent insoluble nitrogen; ADIN, acid detergent insoluble nitrogen; ADF, acid detergent fiber; NDF, neutral detergent fiber; ADL, acid detergent lignin; EE, ether extract; SEM, standard error of the mean.

Means with different superscript (letters) across the column for each parameter are significantly $(\mathrm{p}<0.05)$ different.

Table 2. Secondary compositions of studied browses $(n=6)$

\begin{tabular}{|c|c|c|c|c|c|}
\hline Scientific names & Total phenol & Total non tannin (PVPP) & Total tannin & Condensed tannin & Hydrolysable tannin \\
\hline Acacia nilotica & $167.5^{\mathrm{d}}$ & $54.5^{\mathrm{b}}$ & $113.0^{\mathrm{d}}$ & $48.8^{\mathrm{b}}$ & $64.2^{\mathrm{h}}$ \\
\hline Acacia sieberriana woodii & $113.4^{\mathrm{j}}$ & $17.2^{\mathrm{k}}$ & $96.1^{\mathrm{h}}$ & $37.8^{\mathrm{g}}$ & $58.3^{\mathrm{i}}$ \\
\hline Combretum microphyllum & $134.9^{\mathrm{e}}$ & $19.8^{\mathrm{gh}}$ & $115.2^{\mathrm{c}}$ & $38.6^{\mathrm{f}}$ & $76.6^{\mathrm{e}}$ \\
\hline Combretum molle & $171.7^{\mathrm{c}}$ & $36.9^{\mathrm{e}}$ & $134.7^{\mathrm{b}}$ & $47.7^{\mathrm{c}}$ & $87.0^{\mathrm{d}}$ \\
\hline Euphorbia tirucalli & $100.0^{\mathrm{k}}$ & $18.7^{\mathrm{j}}$ & $81.3^{\mathrm{k}}$ & $5.22^{\mathrm{q}}$ & $76.1^{\mathrm{e}}$ \\
\hline Ficus religiosa & $121.4^{\mathrm{h}}$ & $9.49^{\circ}$ & $111.9^{\mathrm{e}}$ & $18.1^{\mathrm{k}}$ & $93.8^{\mathrm{b}}$ \\
\hline Ficus thronniggi & $34.4^{\mathrm{q}}$ & $7.7^{\mathrm{p}}$ & $26.7^{\circ}$ & $16.0^{1}$ & $10.7^{p}$ \\
\hline Kirkia acuminata & $126.1^{\mathrm{g}}$ & $31.6^{\mathrm{f}}$ & $94.5^{\mathrm{i}}$ & $25.6^{\mathrm{i}}$ & $68.9^{\mathrm{g}}$ \\
\hline Kirkia willmsii & $130.7^{\mathrm{f}}$ & $15.2^{1}$ & $115.5^{\mathrm{c}}$ & $43.4^{\mathrm{d}}$ & $72.1^{\mathrm{f}}$ \\
\hline Lespendeza cuneata & $119.5^{\mathrm{i}}$ & $20.0^{\mathrm{g}}$ & $99.5^{\mathrm{g}}$ & $42.2^{\mathrm{e}}$ & $57.3^{\mathrm{j}}$ \\
\hline Leucaena leucocephala & $99.2^{1}$ & $11.3^{\mathrm{n}}$ & $87.9^{\mathrm{j}}$ & $18.3^{\mathrm{k}}$ & $69.6^{\mathrm{g}}$ \\
\hline Melia azedarach & $32.4^{\mathrm{r}}$ & $19.0^{\mathrm{i}}$ & $13.4^{\mathrm{p}}$ & $6.54^{\mathrm{p}}$ & $6.8^{\mathrm{q}}$ \\
\hline Morus alba & $59.1^{\mathrm{p}}$ & $11.8^{\mathrm{m}}$ & $47.3^{\mathrm{m}}$ & $11.1^{\mathrm{n}}$ & $36.2^{\mathrm{m}}$ \\
\hline Olea europaea & $87.6^{\mathrm{n}}$ & $42.8^{\mathrm{d}}$ & $44.9^{\mathrm{n}}$ & $10.5^{\circ}$ & $34.4^{\mathrm{n}}$ \\
\hline Olea africanum & $88.5^{\mathrm{m}}$ & $43.2^{\mathrm{c}}$ & $45.2^{\mathrm{n}}$ & $12.1^{\mathrm{m}}$ & $33.2^{\circ}$ \\
\hline Peltrophorum africanum & $206.7^{\mathrm{b}}$ & $93.0^{\mathrm{a}}$ & $113.7^{\mathrm{d}}$ & $60.0^{\mathrm{a}}$ & $53.7^{\mathrm{k}}$ \\
\hline Quercus rubica & $126.1^{\mathrm{g}}$ & $19.6^{\mathrm{h}}$ & $106.5^{\mathrm{f}}$ & $18.2^{\mathrm{k}}$ & $88.2^{\mathrm{c}}$ \\
\hline Rhus lancea & $209.1^{\mathrm{a}}$ & $37.2^{\mathrm{e}}$ & $172.0^{\mathrm{a}}$ & $33.0^{\mathrm{h}}$ & $139.0^{\mathrm{a}}$ \\
\hline Ziziphus mucronta & $79.6^{\circ}$ & $11.4^{\mathrm{n}}$ & $68.2^{1}$ & $21.8^{\mathrm{j}}$ & $46.4^{1}$ \\
\hline SEM & 0.24 & 0.078 & 0.25 & 0.16 & 0.313 \\
\hline $\mathrm{p}$ value & $<0.001$ & $<0.001$ & $<0.001$ & $<0.001$ & $<0.001$ \\
\hline
\end{tabular}

PVPP, polyvinyl polypyrrolidone; SEM, standard error of the mean.

Total phenols and tannins were expressed as tannic acid equivalent and condensed tannins as leucocyanidin equivalent.

Means with different superscript (letters) across the column for each parameter are significantly $(\mathrm{p}<0.05)$ different. 
$172 \mathrm{~g} / \mathrm{kg}$ DM while HT concentration ranged between 6.8 to $139 \mathrm{~g} / \mathrm{kg}$ DM. Among the browse species Rhus lancea contained significantly $(\mathrm{p}<0.05)$ the highest concentration of TP, TT, and HT while Peltophorum africanum had the highest concentration of total non tannin and CT. Melia azedarach contained significantly $(\mathrm{p}<0.05)$ the lowest concentrations of TP, TT, CT, and HT.

\section{In vitro gas production and fermentation products}

Gas production: The in vitro GP of studied browse species at different times of incubation $( \pm \mathrm{PEG})$ is shown in Table 3. There was significant $(\mathrm{p}<0.05)$ variation amongst browse species in terms of GP. During the early period of incubation Melia azedarach produced the highest volume of gas, whereas during latter hours (after 12 h) Morus alba produced the highest gas volume. Rhus lancea produced the lowest volume of gas during early period while the lowest volume of gas was recorded for Combretum microphyllum after $12 \mathrm{~h}$. The absence of tannin has significantly $(\mathrm{p}<0.05)$ improved GP for all browses. For instance, the percent increase due to absence of tannins ranged from $1.0 \%$ in Melia azedarach and $121.2 \%$ in Rhus lancea (data not showed).

Morus alba had the highest $(\mathrm{p}<0.05)$ GP from the slowly fermentable organic matter (b value) and potential GP (PD) in absence and presence of tannin (Table 4). The lowest $(\mathrm{p}<0.05)$ b value was recorded for Combretum microphyllum and the lowest PD was recorded in Rhus lancea in absence of tannin. The rate of GP (c) was the highest $\left(9.4 \% \mathrm{~h}^{-1}\right)$ in Leucaena leucocephala and the lowest $\left(2.9 \% \mathrm{~h}^{-1}\right)$ in Rhus lancea. The absence of tannin had significantly improved $b$ and PD values of fermentation kinetics of browses except Ficus religiosa.

Volatile fatty acids and ammonia production: The production of total and individual VFAs varied among browses (Table 5). Morus alba had produced the largest volume of total VFA and acetate. Ziziphus mucronata had produced the highest volume of propionic and valaric acid. Acacia sieberriana had produced the largest volume of isobutric acid while the highest acetate to propionate ratio was recorded for Leucaena leucocephala. The absence of tannin had improved the production of individual and total VFAs.

Production of methane and digestibility: The studied browses differed significantly $(\mathrm{p}<0.05)$ in production of volume $(\mathrm{mL} / \mathrm{g} \mathrm{DM})$ of methane at different incubation periods (Table 6). The volume of $\mathrm{CH}_{4}$ was significantly higher in Melia azedarach during early incubation period (2 to $12 \mathrm{hrs}$ ) and in Ziziphus mucronata and in Morus alba during latter incubation periods. Rhus lancea produced the lowest volume of methane during entire incubation period. The absence of tannin had significantly $(\mathrm{p}<0.05)$ increased the production of methane during all incubation periods for

Table 3. Gas production (mL/400 mg DM) of studied browse plants $(\mathrm{n}=8)$

\begin{tabular}{|c|c|c|c|c|c|c|c|c|}
\hline \multirow{3}{*}{ Scientific names } & \multicolumn{8}{|c|}{ Hrs of incubation } \\
\hline & \multicolumn{2}{|c|}{2} & \multicolumn{2}{|c|}{12} & \multicolumn{2}{|c|}{24} & \multicolumn{2}{|c|}{48} \\
\hline & PEG(-) & PEG(+) & PEG(-) & PEG(+) & PEG(-) & PEG(+) & PEG(-) & $\operatorname{PEG}(+)$ \\
\hline Acacia nilotica & $12.6^{\mathrm{h}}$ & $18.3^{\text {ef }}$ & $27.3^{\mathrm{g}}$ & $52.4^{\mathrm{f}}$ & $32.6^{j}$ & $61.1^{\mathrm{g}}$ & $43.7^{\mathrm{i}}$ & $73.6^{j}$ \\
\hline Acacia sieberriana woodii & $16.8^{\mathrm{d}}$ & $17.9^{\mathrm{f}}$ & $50.4^{\mathrm{d}}$ & $54.3^{\mathrm{e}}$ & $66.3^{\mathrm{d}}$ & $67.9^{\mathrm{e}}$ & $73.8^{\mathrm{c}}$ & $80.6^{\mathrm{h}}$ \\
\hline Combretum microphyllum & $10.6^{\mathrm{i}}$ & $13.7^{\mathrm{i}}$ & $16.6^{1}$ & $25.9^{\mathrm{m}}$ & $18.1^{\mathrm{n}}$ & $28.6^{\mathrm{n}}$ & $24.8^{\mathrm{m}}$ & $41.0^{\mathrm{q}}$ \\
\hline Combretum molle & $12.4^{\mathrm{h}}$ & $18.3^{\mathrm{ef}}$ & $16.4^{1}$ & $30.3^{1}$ & $19.4^{\mathrm{n}}$ & $33.7^{\mathrm{m}}$ & $29.6^{1}$ & $48.5^{\circ}$ \\
\hline Euphorbia tirucalli & $17.5^{\mathrm{c}}$ & $18.9^{\mathrm{de}}$ & $37.9^{\mathrm{e}}$ & $46.4^{\mathrm{g}}$ & $52.6^{\mathrm{e}}$ & $69.5^{\mathrm{d}}$ & $82.9^{\mathrm{d}}$ & $96.0^{\mathrm{d}}$ \\
\hline Ficus religiosa & $10.3^{\mathrm{i}}$ & $16.4^{\mathrm{g}}$ & $26.4^{\mathrm{g}}$ & $36.9^{\mathrm{i}}$ & $45.5^{\mathrm{h}}$ & $57.9^{\mathrm{h}}$ & $62.7^{\mathrm{f}}$ & $75.6^{\mathrm{i}}$ \\
\hline Ficus thronniggi & $14.1^{\mathrm{g}}$ & $15.4^{\mathrm{h}}$ & $58.6^{\mathrm{c}}$ & $59.5^{\mathrm{c}}$ & $76.8^{\mathrm{c}}$ & $79.9^{\mathrm{bc}}$ & $96.0^{\mathrm{b}}$ & $99.6^{\mathrm{b}}$ \\
\hline Kirkia acuminata & $16.0^{\mathrm{ef}}$ & $19.6^{\mathrm{cd}}$ & $18.5^{\mathrm{k}}$ & $30.2^{1}$ & $21.9^{\mathrm{m}}$ & $36.5^{1}$ & $34.6^{\mathrm{j}}$ & $49.7^{\mathrm{n}}$ \\
\hline Kirkia willmsii & $16.3^{\mathrm{de}}$ & $18.2^{\mathrm{ef}}$ & $23.5^{\mathrm{i}}$ & $32.8^{\mathrm{jk}}$ & $28.9^{\mathrm{k}}$ & $39.1^{\mathrm{k}}$ & $43.3^{\mathrm{i}}$ & $54.9^{\mathrm{m}}$ \\
\hline Lespendeza cuneata & $15.6^{\mathrm{f}}$ & $23.5^{\mathrm{b}}$ & $38.7^{\mathrm{e}}$ & $57.6^{\mathrm{d}}$ & $47.8^{\mathrm{f}}$ & $66.1^{\mathrm{f}}$ & $59.5^{\mathrm{g}}$ & $73.0^{\mathrm{j}}$ \\
\hline Leucaena leucocephala & $18.1^{\mathrm{bc}}$ & $19.9^{c}$ & $38.5^{\mathrm{e}}$ & $54.3^{\mathrm{e}}$ & $43.8^{\mathrm{i}}$ & $61.4^{\mathrm{g}}$ & $45.5^{\mathrm{h}}$ & $71.8^{\mathrm{k}}$ \\
\hline Melia azedarach & $26.3^{\mathrm{a}}$ & $28.4^{\mathrm{a}}$ & $68.6^{\mathrm{a}}$ & $70.0^{\mathrm{a}}$ & $78.4^{\mathrm{b}}$ & $79.6^{\mathrm{c}}$ & $87.9^{c}$ & $89.1^{\mathrm{e}}$ \\
\hline Morus alba & $16.7^{\mathrm{de}}$ & $18.8^{\mathrm{de}}$ & $63.2^{\mathrm{b}}$ & $67.0^{\mathrm{b}}$ & $82.3^{\mathrm{a}}$ & $87.0^{\mathrm{a}}$ & $102.0^{\mathrm{a}}$ & $107.1^{\mathrm{a}}$ \\
\hline Olea europaea & $13.9^{\mathrm{h}}$ & $16.2^{\mathrm{gh}}$ & $26.8^{\mathrm{f}}$ & $33.3^{\mathrm{j}}$ & $47.2 \mathrm{f}^{\mathrm{g}}$ & $56.6^{\mathrm{i}}$ & $73.9^{c}$ & $82.0^{\mathrm{g}}$ \\
\hline Olea africanum & $16.0^{\mathrm{ef}}$ & $16.2^{\mathrm{gh}}$ & $29.3^{\mathrm{f}}$ & $33.4^{\mathrm{j}}$ & $46.2^{\mathrm{gh}}$ & $57.0^{\mathrm{hi}}$ & $73.1^{\mathrm{c}}$ & $82.3^{\mathrm{g}}$ \\
\hline Peltrophorum africanum & $10.0^{\mathrm{i}}$ & $14.0^{\mathrm{i}}$ & $21.4^{\mathrm{j}}$ & $32.0^{\mathrm{k}}$ & $23.6^{1}$ & $44.7^{\mathrm{j}}$ & $31.7^{\mathrm{k}}$ & $65.9^{1}$ \\
\hline Quercus rubica & $12.9^{\mathrm{h}}$ & $16.2^{\mathrm{gh}}$ & $24.7^{\mathrm{h}}$ & $33.9^{\mathrm{j}}$ & $29.2^{\mathrm{k}}$ & $37.3^{1}$ & $32.9^{\mathrm{k}}$ & $43.8^{\mathrm{p}}$ \\
\hline Rhus lancea & $7.40^{\mathrm{j}}$ & $11.3^{\mathrm{j}}$ & $11.7^{\mathrm{m}}$ & $44.5^{\mathrm{h}}$ & $13.7^{\circ}$ & $62.0^{\mathrm{g}}$ & $25.7^{\mathrm{m}}$ & $84.3^{\mathrm{f}}$ \\
\hline Ziziphus mucronta & $18.4^{\mathrm{b}}$ & $16.2^{\mathrm{gh}}$ & $62.7^{\mathrm{b}}$ & $59.4^{\mathrm{c}}$ & $82.3^{\mathrm{a}}$ & $80.9^{\mathrm{b}}$ & $101.7^{\mathrm{a}}$ & $100.9^{\mathrm{b}}$ \\
\hline SEM & 0.23 & 0.26 & 0.43 & 0.40 & 0.50 & 0.39 & 0.52 & 0.40 \\
\hline $\mathrm{p}$ value & $<0.001$ & $<0.001$ & $<0.001$ & $<0.001$ & $<0.001$ & $<0.001$ & $<0.001$ & $<0.001$ \\
\hline
\end{tabular}

DM, dry matter; PEG, polyethylene glycol; PEG(-), denotes presence of tannin; PEG(+), denotes absence of tannin; SEM, standard error of the mean. Means with different superscript (letters) across the column for each parameter are significantly $(\mathrm{p}<0.05)$ different. 
Table 4. In vitro gas production characteristics of the studied browse plants $(\mathrm{n}=8)$

\begin{tabular}{|c|c|c|c|c|c|c|}
\hline \multirow{2}{*}{ Scientific name } & \multicolumn{2}{|c|}{$\mathrm{b}^{1}$} & \multicolumn{2}{|c|}{$\mathrm{C}^{2}$} & \multicolumn{2}{|c|}{$\mathrm{PD}^{3}$} \\
\hline & PEG(-) & PEG(+) & PEG(-) & PEG(+) & PEG(-) & $\overline{\mathrm{PEG}(+)}$ \\
\hline$\overline{\text { Acacia nilotica }}$ & $46.0^{\mathrm{m}}$ & $72.2^{1}$ & $0.068^{\mathrm{e}}$ & $0.087^{\mathrm{b}}$ & $26.5^{1}$ & $45.8^{\mathrm{g}}$ \\
\hline Acacia sieberriana woodii & $75.6^{\mathrm{f}}$ & $85.4^{\mathrm{f}}$ & $0.093^{\mathrm{b}}$ & $0.079^{\mathrm{d}}$ & $49.2^{\mathrm{d}}$ & $52.3^{\mathrm{e}}$ \\
\hline Combretum microphyllum & $32.9^{\mathrm{s}}$ & $48.8^{\mathrm{q}}$ & $0.045^{\mathrm{p}}$ & $0.050^{\mathrm{n}}$ & $15.6^{\mathrm{q}}$ & $24.3^{\mathrm{r}}$ \\
\hline Combretum molle & $38.7^{\mathrm{r}}$ & $59.1^{\mathrm{p}}$ & $0.041^{\mathrm{r}}$ & $0.047^{\mathrm{p}}$ & $17.4^{\mathrm{p}}$ & $28.7^{\mathrm{p}}$ \\
\hline Euphorbia tirucalli & $81.0^{\mathrm{e}}$ & $107.8^{\mathrm{d}}$ & $0.057^{\mathrm{i}}$ & $0.056^{\mathrm{k}}$ & $43.1^{\mathrm{f}}$ & $52.2^{\mathrm{e}}$ \\
\hline Ficus religiosa & $61.8^{\mathrm{j}}$ & $74.4^{\mathrm{j}}$ & $0.050^{1}$ & $0.058^{\mathrm{j}}$ & $33.2^{\mathrm{j}}$ & $37.1^{1}$ \\
\hline Ficus thronniggi & $94.3^{\mathrm{c}}$ & $109.7^{\mathrm{c}}$ & $0.049^{\mathrm{m}}$ & $0.060^{\mathrm{h}}$ & $46.7^{\mathrm{e}}$ & $59.7^{\mathrm{c}}$ \\
\hline Kirkia acuminata & $43.4^{\mathrm{n}}$ & $59.7^{\circ}$ & $0.041^{\mathrm{q}}$ & $0.050^{\mathrm{n}}$ & $19.6^{\circ}$ & $30.0^{\circ}$ \\
\hline Kirkia willmsii & $48.1^{\mathrm{k}}$ & $63.3^{\mathrm{n}}$ & $0.051^{\mathrm{k}}$ & $0.052^{\mathrm{m}}$ & $24.5^{\mathrm{m}}$ & $32.1^{\mathrm{n}}$ \\
\hline Lespendeza cuneata & $64.2^{\mathrm{i}}$ & $73.3^{\mathrm{k}}$ & $0.071^{\mathrm{d}}$ & $0.082^{\mathrm{c}}$ & $37.6^{\mathrm{g}}$ & $45.4^{\mathrm{h}}$ \\
\hline Leucaena leucocephala & $46.1^{1}$ & $76.3^{\mathrm{i}}$ & $0.094^{\mathrm{a}}$ & $0.072^{\mathrm{e}}$ & $30.1^{\mathrm{k}}$ & $45.0^{\mathrm{i}}$ \\
\hline Melia azedarach & $94.2^{\mathrm{d}}$ & $94.3^{\mathrm{e}}$ & $0.062^{\mathrm{g}}$ & $0.064^{\mathrm{g}}$ & $52.1^{\mathrm{c}}$ & $52.9^{\mathrm{d}}$ \\
\hline Morus alba & $110.7^{\mathrm{a}}$ & $116.1^{\mathrm{a}}$ & $0.064^{\mathrm{f}}$ & $0.066^{\mathrm{f}}$ & $62.1^{\mathrm{a}}$ & $65.8^{\mathrm{a}}$ \\
\hline Olea europaea & $73.4^{\mathrm{g}}$ & $79.8^{\mathrm{h}}$ & $0.047^{\circ}$ & $0.057^{\mathrm{k}}$ & $35.6^{\mathrm{i}}$ & $42.6^{\mathrm{k}}$ \\
\hline Olea africanum & $72.7^{\mathrm{h}}$ & $80.3^{\mathrm{g}}$ & $0.052^{\mathrm{j}}$ & $0.057^{\mathrm{k}}$ & $37.2^{\mathrm{h}}$ & $42.8^{\mathrm{j}}$ \\
\hline Peltrophorum africanum & $39.8^{\circ}$ & $69.5^{\mathrm{m}}$ & $0.048^{\mathrm{n}}$ & $0.056^{1}$ & $19.5^{\mathrm{n}}$ & $36.8^{1}$ \\
\hline Quercus rubica & $38.2^{\mathrm{q}}$ & $43.6^{\mathrm{r}}$ & $0.082^{\mathrm{c}}$ & $0.089^{\mathrm{a}}$ & $23.7^{\mathrm{n}}$ & $27.9^{\mathrm{q}}$ \\
\hline Rhus lancea & $38.5^{\mathrm{p}}$ & $94.3^{\mathrm{e}}$ & $0.029^{\mathrm{s}}$ & $0.049^{\circ}$ & $14.0^{\mathrm{q}}$ & $46.9 f$ \\
\hline Ziziphus mucronta & $110.0^{\mathrm{b}}$ & $110.9^{\mathrm{b}}$ & $0.061^{\mathrm{h}}$ & $0.059^{\mathrm{i}}$ & $60.3^{\mathrm{b}}$ & $60.2^{\mathrm{b}}$ \\
\hline SEM & 0.458 & 0.81 & 0.0035 & 0.004 & 0.15 & 0.24 \\
\hline $\mathrm{p}$ value & $<0.001$ & $<0.001$ & $<0.001$ & $<0.001$ & $<0.001$ & $<0.001$ \\
\hline
\end{tabular}

PEG, polyethylene glycol; PEG(-), denotes presence of tannin; PEG(+), denotes absence of tannin; SEM, standard error of the mean.

${ }^{1} \mathrm{~b}$, gas production from the insoluble but slowly fermentable/degradable fraction $(\mathrm{mL})$.

${ }^{2} \mathrm{C}$, the rate of GP from insoluble fraction per hour.

${ }^{3} \mathrm{PD}$, potential gas production $(\mathrm{mL})$.

Means with different superscript (letters) across the column for each parameter are significantly $(\mathrm{p}<0.05)$ different.

all browses.

Methane production expressed in mass (methane production $\mathrm{g} / \mathrm{kg} \mathrm{DM}$ and $\mathrm{g} / \mathrm{kg}$ IVOMD) and methane expressed as lost energy were also varied significantly $(\mathrm{p}<0.05)$ amongst the browses (Table 7). Morus alba and Ziziphus mucronata produced the highest amount of

Table 5. Total and individual volatile fatty acid (mM/L) production, in supernatant after $72 \mathrm{~h}$ incubation of $400 \mathrm{mg}$ DM of browses with or without PEG

\begin{tabular}{|c|c|c|c|c|c|c|c|c|c|c|c|c|}
\hline \multirow{2}{*}{ Scientific name } & \multicolumn{2}{|c|}{ Acetic } & \multicolumn{2}{|c|}{ Propionic } & \multicolumn{2}{|c|}{ Iso butyric } & \multicolumn{2}{|c|}{ Butyric } & \multicolumn{2}{|c|}{ Valeric } & \multicolumn{2}{|c|}{ Total VFA } \\
\hline & PEG(-) & PEG(+) & PEG(-) & PEG(+) & PEG(-) & $\operatorname{PEG(+)}$ & PEG(-) & $\operatorname{PEG(+)}$ & PEG(-) & $\operatorname{PEG(+)}$ & PEG(-) & PEG(+) \\
\hline Acacia nilotica & 45.0 & 52.2 & 14.13 & 13.09 & 1.16 & 1.73 & 2.86 & 4.55 & 1.58 & 2.21 & 64.7 & 73.7 \\
\hline Acacia sieberriana woodii & 47.5 & 57.6 & 12.13 & 14.01 & 2.36 & 2.76 & 5.35 & 5.42 & 2.25 & 2.53 & 69.6 & 82.2 \\
\hline Combretum microphyllum & 47.6 & 58.1 & 10.18 & 15.19 & 1.49 & 2.36 & 3.61 & 7.25 & 1.75 & 2.57 & 64.6 & 85.5 \\
\hline Combretum molle & 43.4 & 48.8 & 9.12 & 9.66 & 1.09 & 1.25 & 2.70 & 2.69 & 1.40 & 1.50 & 57.7 & 63.9 \\
\hline Euphorbia tirucalli & 72.4 & 76.9 & 16.26 & 16.89 & 1.89 & 2.12 & 8.53 & 9.28 & 2.41 & 2.57 & 101.5 & 107.8 \\
\hline Ficus religiosa & 53.4 & 63.0 & 11.59 & 13.48 & 1.59 & 1.94 & 4.35 & 5.42 & 1.89 & 2.13 & 72.8 & 86.0 \\
\hline Ficus thronniggi & 71.9 & 75.4 & 15.49 & 16.57 & 2.27 & 2.34 & 6.62 & 7.16 & 2.48 & 2.79 & 98.7 & 104.2 \\
\hline Lespendeza cuneata & 46.7 & 61.6 & 11.67 & 15.09 & 1.51 & 2.36 & 3.47 & 5.84 & 2.12 & 2.97 & 65.5 & 87.9 \\
\hline Leucaena leucocephala & 55.9 & 58.1 & 13.63 & 13.64 & 1.69 & 1.83 & 4.79 & 5.46 & 2.20 & 2.45 & 78.2 & 81.5 \\
\hline Kirkia acuminata & 44.4 & 54.4 & 10.17 & 12.58 & 1.13 & 1.15 & 3.50 & 4.35 & 0.59 & 0.99 & 59.8 & 73.4 \\
\hline Kirkia willmsii & 53.2 & 62.9 & 12.87 & 14.23 & 0.92 & 1.50 & 3.79 & 4.68 & 0.85 & 1.68 & 71.7 & 85.0 \\
\hline Melia azedarach & 58.1 & 63.0 & 15.19 & 16.18 & 2.36 & 2.41 & 7.25 & 7.96 & 2.57 & 2.85 & 85.5 & 92.4 \\
\hline Morus alba & 72.5 & 73.7 & 16.80 & 17.42 & 2.33 & 2.43 & 7.37 & 7.85 & 2.51 & 2.70 & 101.5 & 104.1 \\
\hline Olea africanum & 42.5 & 44.1 & 9.50 & 9.46 & 1.32 & 1.37 & 5.62 & 5.50 & 1.70 & 1.64 & 60.7 & 62.1 \\
\hline Olea europaea & 53.5 & 61.3 & 11.68 & 12.9 & 1.66 & 1.87 & 7.30 & 7.82 & 2.09 & 2.26 & 76.3 & 86.2 \\
\hline Peltrophorum africanum & 48.2 & 52.8 & 10.77 & 12.42 & 1.55 & 2.18 & 2.82 & 5.15 & 1.70 & 2.39 & 65.0 & 75.0 \\
\hline Quercus rubica & 45.5 & 49.1 & 9.71 & 10.76 & 1.13 & 1.35 & 3.94 & 4.72 & 1.51 & 1.68 & 61.7 & 67.6 \\
\hline Rhus lancea & 42.2 & 63.9 & 9.65 & 12.79 & 1.17 & 1.95 & 4.39 & 5.54 & 1.21 & 2.11 & 58.6 & 86.3 \\
\hline Ziziphus mисronta & 69.8 & 67.8 & 18.52 & 18.17 & 2.18 & 2.17 & 7.75 & 7.66 & 2.60 & 2.47 & 100.8 & 98.3 \\
\hline
\end{tabular}

DM, dry matter; PEG, poly-ethylene glycol; VFA, volatile fatty acid; PEG(-), denotes presence of tannin; PEG(+), denotes absence of tannin. 
Table 6. Volumes (mL/g DM) of methane production from the studied browse plants $(\mathrm{n}=8)$

\begin{tabular}{|c|c|c|c|c|c|c|c|c|}
\hline \multirow{3}{*}{ Scientific name } & \multicolumn{8}{|c|}{ Time of incubation } \\
\hline & \multicolumn{2}{|c|}{2} & \multicolumn{2}{|c|}{12} & \multicolumn{2}{|c|}{24} & \multicolumn{2}{|c|}{48} \\
\hline & PEG(-) & PEG(+) & PEG(-) & PEG(+) & PEG(-) & PEG(+) & PEG(-) & PEG(+) \\
\hline Acacia nilotica & $0.76^{\mathrm{h}}$ & $1.70^{f}$ & $3.43^{\mathrm{m}}$ & $8.46^{\mathrm{j}}$ & $4.55^{\mathrm{k}}$ & $17.83^{\mathrm{e}}$ & $5.10^{\mathrm{ij}}$ & $19.46^{\mathrm{f}}$ \\
\hline Acacia sieberriana woodii & $1.15^{\mathrm{d}}$ & $1.50^{\mathrm{g}}$ & $9.93^{\mathrm{e}}$ & $11.15^{\mathrm{e}}$ & $15.33^{\mathrm{c}}$ & $17.27^{\mathrm{f}}$ & $16.41^{\mathrm{f}}$ & $21.66^{\mathrm{e}}$ \\
\hline Combretum microphyllum & $0.078^{\mathrm{n}}$ & $0.95^{\mathrm{k}}$ & $2.08^{\mathrm{p}}$ & $4.31^{\mathrm{r}}$ & $2.13^{\mathrm{m}}$ & $4.64^{\mathrm{p}}$ & $2.93^{\mathrm{m}}$ & $7.53^{\mathrm{k}}$ \\
\hline Combretum molle & $0.091^{\mathrm{m}}$ & $1.85^{1}$ & $2.44^{\circ}$ & $5.96^{\mathrm{n}}$ & $2.52^{\circ}$ & $5.46^{\circ}$ & $4.21^{\mathrm{k}}$ & $10.69^{\mathrm{i}}$ \\
\hline Euphorbia tirucalli & $1.01^{\mathrm{e}}$ & $2.03^{\mathrm{c}}$ & $6.94^{\mathrm{f}}$ & $10.20^{\mathrm{h}}$ & $11.39^{\mathrm{d}}$ & $16.94^{\mathrm{g}}$ & $21.41^{\mathrm{c}}$ & $26.21^{\mathrm{c}}$ \\
\hline Ficus religiosa & $0.28^{\mathrm{k}}$ & $1.04^{\mathrm{j}}$ & $4.23^{\mathrm{k}}$ & $7.71^{\mathrm{k}}$ & $8.91^{\mathrm{h}}$ & $14.11^{\mathrm{i}}$ & $13.2^{\mathrm{g}}$ & $18.18^{\mathrm{g}}$ \\
\hline Ficus thronniggi & $1.51^{\mathrm{c}}$ & $1.90^{\mathrm{d}}$ & $11.94^{\mathrm{d}}$ & $13.47^{\mathrm{d}}$ & $18.45^{\mathrm{b}}$ & $20.28^{\mathrm{d}}$ & $26.11^{\mathrm{b}}$ & $28.25^{\mathrm{b}}$ \\
\hline Kirkia acuminata & $0.15^{1}$ & $0.94^{\mathrm{k}}$ & $0.77^{\mathrm{r}}$ & $3.91^{\mathrm{q}}$ & $1.65^{\mathrm{no}}$ & $4.61^{\mathrm{p}}$ & $3.56^{1}$ & $8.07^{\mathrm{kj}}$ \\
\hline Kirkia willmsii & $0.30^{\mathrm{k}}$ & $0.89^{1}$ & $2.75^{\circ}$ & $5.10^{\mathrm{p}}$ & $3.23^{1}$ & $5.93^{\mathrm{n}}$ & $5.20^{\mathrm{i}}$ & $9.25^{\mathrm{j}}$ \\
\hline Lespendeza cuneata & $0.45^{\mathrm{i}}$ & $1.77^{\mathrm{e}}$ & $5.88^{\mathrm{h}}$ & $10.44^{\mathrm{fg}}$ & $10.72^{\mathrm{e}}$ & $17.16^{\mathrm{fg}}$ & $13.42^{\mathrm{g}}$ & $19.56^{\mathrm{f}}$ \\
\hline Leucaena leucocephala & $2.08^{\mathrm{b}}$ & $2.36^{\mathrm{b}}$ & $6.30^{\mathrm{g}}$ & $10.3^{\mathrm{g}}$ & $7.99^{\mathrm{i}}$ & $13.23^{\mathrm{j}}$ & $8.86^{\mathrm{h}}$ & $21.69^{f}$ \\
\hline Melia azedarach & $3.12^{\mathrm{a}}$ & $3.54^{\mathrm{a}}$ & $15.10^{\mathrm{a}}$ & $16.84^{\mathrm{a}}$ & $18.37^{\mathrm{b}}$ & $20.82^{\mathrm{c}}$ & $21.17^{\mathrm{c}}$ & $24.39^{\mathrm{d}}$ \\
\hline Morus alba & $0.40^{\mathrm{j}}$ & $0.95^{\mathrm{k}}$ & $13.61^{\mathrm{c}}$ & $14.98^{\mathrm{b}}$ & $20.67^{\mathrm{a}}$ & $22.26^{\mathrm{a}}$ & $29.1^{\mathrm{a}}$ & $30.35^{\mathrm{a}}$ \\
\hline Olea africanum & $1.11^{\mathrm{d}}$ & $1.40^{\mathrm{h}}$ & $4.99^{\mathrm{i}}$ & $6.60^{1}$ & $9.89^{\mathrm{f}}$ & $12.41^{\mathrm{k}}$ & $18.15^{\mathrm{d}}$ & $21.83^{\mathrm{e}}$ \\
\hline Olea europaea & $0.95^{\mathrm{f}}$ & $1.26^{\mathrm{i}}$ & $4.47^{\mathrm{j}}$ & $6.56^{1}$ & $9.51^{\mathrm{g}}$ & $12.31^{\mathrm{k}}$ & $17.51^{\mathrm{e}}$ & $21.74^{\mathrm{e}}$ \\
\hline Peltrophorum africanum & $0.080^{\mathrm{n}}$ & $0.84^{1}$ & $1.62^{\mathrm{q}}$ & $6.03^{\mathrm{m}}$ & $1.75^{\mathrm{n}}$ & $9.13^{1}$ & $3.78^{1}$ & $16.64^{\mathrm{h}}$ \\
\hline Quercus rubica & $0.84^{\mathrm{g}}$ & $1.42^{\mathrm{h}}$ & $3.63^{1}$ & $5.79^{\circ}$ & $5.17^{\mathrm{j}}$ & $7.74^{\mathrm{m}}$ & $4.79^{\mathrm{j}}$ & $9.10^{\mathrm{j}}$ \\
\hline Rhus lancea & $0.058^{\circ}$ & $0.12^{1}$ & $0.04^{\mathrm{s}}$ & $8.62 \mathrm{i}$ & $0.10^{\mathrm{p}}$ & $14.45^{\mathrm{h}}$ & $2.21^{\mathrm{m}}$ & $22.58^{\mathrm{e}}$ \\
\hline Ziziphus mucronta & $1.12^{\mathrm{d}}$ & $0.88^{1}$ & $12.98^{\mathrm{b}}$ & $13.85^{\mathrm{c}}$ & $20.64^{\mathrm{a}}$ & $21.24^{\mathrm{b}}$ & $28.74^{\mathrm{a}}$ & $30.36^{\mathrm{a}}$ \\
\hline SEM & 0.015 & 0.0087 & 0.0074 & 0.0194 & 0.056 & 0.093 & 0.135 & 0.397 \\
\hline $\mathrm{p}$ value & $<0.001$ & $<0.001$ & $<0.001$ & $<0.001$ & $<0.001$ & $<0.001$ & $<0.001$ & $<0.001$ \\
\hline
\end{tabular}

DM, dry matter; PEG, poly-ethylene glycol; PEG(-), denotes presence of tannin; PEG(+), denotes absence of tannin; SEM, standard error of the mean.

Means with different superscript (letters) across the column for each parameter are significantly $(\mathrm{p}<0.05)$ different.

Table 7. Methane $\left(\mathrm{CH}_{4}\right)$ production in mass ( $\mathrm{g} / \mathrm{kg} \mathrm{DM}$, methane per $\mathrm{g} / \mathrm{kg}$ IVOMD) and percent of energy lost as $\mathrm{CH}_{4}(\% \mathrm{ME})$ from the studied browse plants after $24 \mathrm{~h}$ of incubation

\begin{tabular}{|c|c|c|c|c|c|c|}
\hline \multirow{2}{*}{ Scientific name } & \multicolumn{2}{|c|}{ Methane (g/kg DM) } & \multicolumn{2}{|c|}{ Methane (g/kg IVOMD) } & \multicolumn{2}{|c|}{ lost energy as $\mathrm{CH}_{4}(\% \mathrm{ME})$} \\
\hline & PEG(-) & $(\mathrm{PEG}+)$ & PEG(-) & $(\mathrm{PEG}+)$ & PEG(-) & $(\mathrm{PEG}+)$ \\
\hline$\overline{\text { Acacia nilotica }}$ & $3.26^{\mathrm{m}}$ & $11.0^{\mathrm{e}}$ & $7.77^{1}$ & $14.9^{\mathrm{e}}$ & $1.29^{\top}$ & $2.41^{j}$ \\
\hline Acacia sieberriana woodii & $6.66^{\mathrm{h}}$ & $10.9^{f}$ & $9.59^{j}$ & $13.0^{\mathrm{i}}$ & $2.62^{\mathrm{e}}$ & $2.68^{\mathrm{f}}$ \\
\hline Combretum microphyllum & $1.53^{\mathrm{p}}$ & $3.19^{\mathrm{r}}$ & $3.07^{\mathrm{q}}$ & $4.64^{\mathrm{r}}$ & $0.72^{\mathrm{r}}$ & $1.13^{\mathrm{s}}$ \\
\hline Combretum molle & $1.80^{\circ}$ & $3.91^{\mathrm{p}}$ & $3.98^{\circ}$ & $5.18^{\mathrm{p}}$ & $0.76^{\mathrm{q}}$ & $1.33^{\mathrm{r}}$ \\
\hline Euphorbia tirucalli & $7.09^{\mathrm{e}}$ & $11.4^{\mathrm{d}}$ & $13.0^{\mathrm{a}}$ & $15.3^{\mathrm{d}}$ & $2.08^{\mathrm{f}}$ & $2.74^{\mathrm{e}}$ \\
\hline Ficus religiosa & $6.38^{\mathrm{i}}$ & $10.1^{\mathrm{i}}$ & $10.2^{f}$ & $12.9^{\mathrm{j}}$ & $1.80^{\mathrm{i}}$ & $2.29^{\mathrm{k}}$ \\
\hline Ficus thronniggi & $7.48^{\mathrm{c}}$ & $11.8^{\mathrm{c}}$ & $11.0^{\mathrm{d}}$ & $15.7^{\mathrm{c}}$ & $3.04^{\mathrm{d}}$ & $3.16^{\mathrm{c}}$ \\
\hline Kirkia acuminata & $1.18^{\mathrm{r}}$ & $3.30^{\mathrm{q}}$ & $2.29^{\mathrm{r}}$ & $4.03^{\mathrm{s}}$ & $0.86^{\mathrm{p}}$ & $1.44^{\mathrm{q}}$ \\
\hline Kirkia willmsii & $2.31^{\mathrm{n}}$ & $4.25^{\circ}$ & $4.86^{\mathrm{n}}$ & $5.11^{\mathrm{q}}$ & $1.14^{\mathrm{n}}$ & $1.54^{\mathrm{o}}$ \\
\hline Lespendeza cuneata & $6.24^{\mathrm{j}}$ & $10.1^{\mathrm{h}}$ & $9.69^{\mathrm{i}}$ & $13.4^{\mathrm{g}}$ & $1.89^{\mathrm{g}}$ & $2.61^{\mathrm{g}}$ \\
\hline Leucaena leucocephala & $4.29^{1}$ & $9.47^{\mathrm{j}}$ & $6.30^{\mathrm{m}}$ & $10.8^{1}$ & $1.73^{\mathrm{k}}$ & $2.43^{\mathrm{i}}$ \\
\hline Melia azedarach & $7.28^{\mathrm{d}}$ & $11.5^{\mathrm{c}}$ & $11.7^{\mathrm{c}}$ & $14.8^{\mathrm{f}}$ & $3.10^{\mathrm{c}}$ & $3.14^{\mathrm{d}}$ \\
\hline Morus alba & $9.59^{\mathrm{a}}$ & $12.5^{\mathrm{a}}$ & $12.6^{\mathrm{b}}$ & $17.2^{\mathrm{a}}$ & $3.25^{\mathrm{a}}$ & $3.44^{\mathrm{a}}$ \\
\hline Olea africanum & $7.08^{\mathrm{k}}$ & $8.89^{\mathrm{k}}$ & $9.87^{\mathrm{g}}$ & $10.7^{\mathrm{m}}$ & $1.82^{\mathrm{h}}$ & $2.25^{1}$ \\
\hline Olea europaea & $6.81^{\mathrm{g}}$ & $8.81^{1}$ & $9.73^{\mathrm{h}}$ & $11.2^{\mathrm{k}}$ & $1.76^{\mathrm{j}}$ & $2.24^{\mathrm{m}}$ \\
\hline Peltrophorum africanum & $1.25^{\mathrm{q}}$ & $6.54^{\mathrm{m}}$ & $3.76^{\mathrm{p}}$ & $10.1^{\mathrm{n}}$ & $0.93^{\circ}$ & $1.77^{\mathrm{n}}$ \\
\hline Quercus rubica & $5.13^{\mathrm{k}}$ & $5.54^{\mathrm{n}}$ & $8.92^{\mathrm{k}}$ & $7.34^{\circ}$ & $1.15^{\mathrm{m}}$ & $1.47^{\mathrm{p}}$ \\
\hline Rhus lancea & $0.07^{\mathrm{s}}$ & $10.4^{\mathrm{g}}$ & $0.22^{\mathrm{s}}$ & $13.3^{\mathrm{h}}$ & $0.54^{\mathrm{s}}$ & $2.45^{\mathrm{h}}$ \\
\hline Ziziphus mucronta & $8.56^{\mathrm{b}}$ & $12.0^{\mathrm{b}}$ & $10.9^{\mathrm{e}}$ & $16.6^{\mathrm{b}}$ & $3.25^{\mathrm{b}}$ & $3.20^{\mathrm{b}}$ \\
\hline SEM & 0.067 & 0.09 & 0.086 & 0.067 & 0.02 & 0.019 \\
\hline $\mathrm{p}$ value & $<0.001$ & $<0.001$ & $<0.001$ & $<0.001$ & $<0.001$ & $<0.001$ \\
\hline
\end{tabular}

DM, dry matter; IVOMD, in vitro organic matter digestibility; ME, metabolizable energy; PEG, polyethylene glycol; PEG(-), denotes presence of tannin; PEG(+), denotes absence of tannin; SEM, standard error of the mean.

Means with different superscript (letters) across the column for each parameter are significantly $(\mathrm{p}<0.05)$ different. 
methane expressed in mass (methane production $\mathrm{g} / \mathrm{kg} \mathrm{DM}$ and $\mathrm{g} / \mathrm{kg}$ IVOMD) and lost energy as methane. On the other hand high tannin containing plants, Rhus lancea, Kirkia acuminate and Combretum microphyllum produced lowest values of methane expressed in volumes, mass and wasted energy. The absence of tannin had increased methane production that was depressed by tannins. The highest increment was recorded in Rhus lancea while the lowest increment was observed for low methane producing browses (Ziziphus mucronata and Melia azedarach). On the other hand methane production per digested DM was substantially decreased for high tannin containing browses in the absence of tannin while slight increment was observed for low tannin containing browses.

The studied browses significantly $(\mathrm{p}<0.05)$ varied in their IVOMD and ME content (Table 8). Browses with high tannin content were found to be low in digestibility, and Peltrophorum Africanum and Rhus lancea were the least digestible browses. There was a significant $(\mathrm{p}<0.05)$ increment in values of IVOMD and ME in absence of tannin. The production of ammonia from browses was differed significantly $(\mathrm{p}<0.05)$ for studied browses. The highest ammonia concentration was recorded for Morus alba, while the lowest value was recorded for Kirkia acuminate. A pronounced improvement of ammonia concentration was obtained in the absence of tannin.
Correlation of in vitro organic matter digestibility and methane with chemical composition and phenolic compounds

The correlations coefficient values for IVOMD with chemical composition, GP, phenolic compounds, short chain VFA and $\mathrm{NH}_{3}$ from browse species are presented in Table 9. Significantly $(p<0.001)$ positive correlations were observed between IVOMD and ash and nitrogen content, GP $\left(\mathrm{Gp}_{24}\right.$ and $\left.\mathrm{Gp}_{48}\right), \mathrm{ME}$, and total and individual VFAs. There was a significant $(\mathrm{p}<0.001)$ and negative correlation of IVOMD with fiber component (ADF) and phenolic compounds (TP, TT, CT, and HT).

Correlation coefficients (r) between chemical composition and phenolic compounds with methane production parameters of studied browse plants were shown in Table 10. Methane production at $24 \mathrm{~h}$ and total methane production had shown similar pattern of correlation with chemical and phenolic composition of browses. However, the relative increase in methane production in absence of tannin showed opposite trend with absolute and net methane production. Methane production at $24 \mathrm{~h}$ showed significantly $(\mathrm{p}<0.001)$ negative correlation with phenolic compounds (TP, TT, CT, and HT) and positive correlation with fiber components. Increase in methane production, in absence of tannin showed positive correlation with phenolic compounds and negative correlation with fiber components

Table 8. In vitro organic matter digestibility (IVOMD, g/kg DM), metabolizable energy (ME, MJ/kg DM) ammonia N (mmol/100 mL) from the studied browse plants

\begin{tabular}{|c|c|c|c|c|c|c|}
\hline \multirow{2}{*}{ Scientific name } & \multicolumn{2}{|c|}{ IVOMD } & \multicolumn{2}{|c|}{$\mathrm{NH}_{3} \mathrm{~N}$} & \multicolumn{2}{|c|}{$\mathrm{ME}$} \\
\hline & PEG(-) & $(\mathrm{PEG}+)$ & PEG(-) & $(\mathrm{PEG}+)$ & PEG(-) & (PEG+) \\
\hline$\overline{\text { Acacia nilotica }}$ & $419.0^{\mathrm{q}}$ & $758.5^{\mathrm{n}}$ & $13.5^{\text {ih }}$ & $18.9^{\mathrm{d}}$ & $10.2^{\mathrm{f}}$ & $23.4^{\mathrm{j}}$ \\
\hline Acacia sieberriana woodii & $694.6^{\mathrm{g}}$ & $838.2^{\mathrm{e}}$ & $16.8^{\mathrm{ef}}$ & $17.9^{\mathrm{e}}$ & $11.2^{\mathrm{e}}$ & $41.3^{\mathrm{c}}$ \\
\hline Combretum microphyllum & $496.7^{\mathrm{m}}$ & $688.8^{r}$ & $15.7^{\mathrm{f}}$ & $17.9^{\mathrm{e}}$ & $6.66^{\circ}$ & $24.8^{\mathrm{i}}$ \\
\hline Combretum molle & $453.9^{\mathrm{p}}$ & $755.3^{\mathrm{d}}$ & $17.2^{\mathrm{de}}$ & $17.9^{\mathrm{e}}$ & $7.07^{\mathrm{n}}$ & $20.2^{\mathrm{k}}$ \\
\hline Euphorbia tirucalli & $479.2^{\mathrm{n}}$ & $792.5^{\mathrm{j}}$ & $18.5^{\mathrm{c}}$ & $18.9^{\mathrm{d}}$ & $9.02^{\mathrm{g}}$ & $14.4^{\mathrm{q}}$ \\
\hline Ficus religiosa & $584.3^{\mathrm{j}}$ & $785.5^{1}$ & $20.1^{\mathrm{b}}$ & $20.8^{\mathrm{b}}$ & $7.94^{\mathrm{i}}$ & $19.6^{\mathrm{m}}$ \\
\hline Ficus thronniggi & $776.2^{\mathrm{c}}$ & $835.3^{f}$ & $20.4^{\mathrm{b}}$ & $21.0^{\mathrm{b}}$ & $11.9^{c}$ & $40.3^{\mathrm{d}}$ \\
\hline Kirkia acuminata & $515.8^{1}$ & $819.3^{\mathrm{i}}$ & $3.88^{1}$ & $9.10^{\mathrm{i}}$ & $7.04^{\mathrm{n}}$ & $19.9^{1}$ \\
\hline Kirkia willmsii & $475.8^{\circ}$ & $830.6^{\mathrm{g}}$ & $10.4^{\mathrm{k}}$ & $13.9^{\mathrm{g}}$ & $7.25^{\mathrm{m}}$ & $16.4^{\mathrm{o}}$ \\
\hline Lespendeza cuneata & $644.2^{\mathrm{i}}$ & $757.6^{\circ}$ & $16.2^{\mathrm{f}}$ & $17.9^{\mathrm{e}}$ & $11.3^{\mathrm{e}}$ & $31.7^{\mathrm{f}}$ \\
\hline Leucaena leucocephala & $681.0^{\mathrm{h}}$ & $877.0^{\mathrm{d}}$ & $11.9^{\mathrm{j}}$ & $13.2^{\mathrm{h}}$ & $11.3^{\mathrm{e}}$ & $43.8^{\mathrm{a}}$ \\
\hline Melia azedarach & $746.1^{\mathrm{d}}$ & $882.5^{\mathrm{c}}$ & $18.2^{\mathrm{c}}$ & $19.6^{\mathrm{c}}$ & $13.4^{\mathrm{a}}$ & $43.2^{\mathrm{b}}$ \\
\hline Morus alba & $805.7^{\mathrm{b}}$ & $929.0^{\mathrm{a}}$ & $21.3^{\mathrm{a}}$ & $22.3^{\mathrm{a}}$ & $12.3^{\mathrm{b}}$ & $25.7^{\mathrm{h}}$ \\
\hline Olea europaea & $700.1^{\mathrm{f}}$ & $789.9^{j}$ & $14.1^{\mathrm{g}}$ & $15.9^{\mathrm{f}}$ & $7.39^{1}$ & $15.0^{\mathrm{p}}$ \\
\hline Olea africanum & $717.3^{\mathrm{e}}$ & $830.5^{\mathrm{h}}$ & $13.7^{\mathrm{h}}$ & $15.4^{\mathrm{fg}}$ & $7.39^{1}$ & $17.6^{\mathrm{n}}$ \\
\hline Peltrophorum africanum & $333.3^{r}$ & $647.5^{\mathrm{s}}$ & $14.3^{\mathrm{g}}$ & $18.0^{\mathrm{e}}$ & $7.53^{\mathrm{k}}$ & $25.7^{\mathrm{h}}$ \\
\hline Quercus rubica & $575.4^{\mathrm{k}}$ & $754.8^{\mathrm{q}}$ & $13.6^{\text {ih }}$ & $15.4^{\mathrm{fg}}$ & $7.82^{\mathrm{j}}$ & $26.7^{\mathrm{g}}$ \\
\hline Rhus lancea & $324.0^{\mathrm{s}}$ & $776.0^{\mathrm{m}}$ & $12.2^{\mathrm{j}}$ & $18.2^{\mathrm{de}}$ & $8.74^{\mathrm{h}}$ & $14.2^{\mathrm{r}}$ \\
\hline Ziziphus mucronta & $894.3^{\mathrm{a}}$ & $919.0^{\mathrm{b}}$ & $18.1^{\mathrm{c}}$ & $18.8^{\mathrm{d}}$ & $11.7^{\mathrm{d}}$ & $35.6^{\mathrm{e}}$ \\
\hline SEM & 0.190 & 0.21 & 0.2106 & 0.158 & 0.01 & 0.01 \\
\hline $\mathrm{p}$ value & $<0.001$ & $<0.001$ & $<0.001$ & $<0.001$ & $<0.001$ & $<0.001$ \\
\hline
\end{tabular}

DM, dry matter; PEG, poly-ethylene glycol; PEG(-), denotes presence of tannin; PEG(+), denotes absence of tannin; SEM, standard error of the mean. Means with different superscript (letters) across the column for each parameter are significantly $(\mathrm{p}<0.05)$ different. 
Table 9. Correlation coefficients ( $\mathrm{r}$ ) between in vitro fermentation parameters with chemical composition and phenolic compounds of studied browse plants

\begin{tabular}{|c|c|c|c|c|c|c|}
\hline & $\mathrm{IVGP}_{24}$ & $\mathrm{IVGP}_{48}$ & $\mathrm{NH}_{3}-\mathrm{N}$ & VFA & IVOMD & $\mathrm{ME}$ \\
\hline \multicolumn{7}{|c|}{ Chemical composition } \\
\hline Ash & $0.501 * * *$ & $0.523 * * *$ & $0.654 * * *$ & $0.732 * * *$ & $0.297 *$ & $0.488 * * *$ \\
\hline $\mathrm{EE}$ & -0.102 & -0.112 & 0.027 & $0.351 *$ & 0.0458 & 0.121 \\
\hline $\mathrm{CP}$ & $0.588 * * *$ & $0.362 * *$ & $0.292 *$ & $0.352 *$ & $0.372 * *$ & $0.767 * * *$ \\
\hline $\mathrm{NDF}$ & $-0.350 *$ & $-0.414 * * *$ & $-0.417 * * *$ & -0.138 & -0.427 & $-0.247 *$ \\
\hline $\mathrm{ADF}$ & $-0.605 * * *$ & $-0.619 * * *$ & $-0.453 * * *$ & 0.012 & $-0.619 * * *$ & $-0.456 * * *$ \\
\hline $\mathrm{ADL}$ & $-0.620 * * *$ & $-0.698 * * *$ & -0.182 & -0.100 & $-0.326^{*}$ & -0.124 \\
\hline \multicolumn{7}{|c|}{ Secondary compounds } \\
\hline $\mathrm{TP}$ & $-0.833 * * *$ & $-0.825 * * *$ & $-0.43 * * *$ & $-0.676 * * *$ & $-0.641 * * *$ & $-0.417 * * *$ \\
\hline $\mathrm{TT}$ & $-0.782 * * *$ & $-0.739 * * *$ & $-0.329 *$ & $-0.566 * * *$ & $-0.630 * * *$ & $-0.514 * * *$ \\
\hline CT & $-0.566 * * *$ & $-0.632 * * *$ & $-0.366 * *$ & $-0.545 * * *$ & $-0.702 * * *$ & $-0.301 *$ \\
\hline HT & $-0.706^{* * *}$ & $-0.691 * * *$ & $-0.324 *$ & $-0.423 * *$ & $-0.439 * * *$ & $-0.499 * * *$ \\
\hline
\end{tabular}

IVGP, in vitro gas production; VFA, volatile fatty acid; IVOMD, in vitro organic matter digestibility; ME, metabolizable energy; EE, ether extract; CP, crude protein; NDF, neutral detergent fiber; ADF, acid detergent fiber; ADL, acid detergent lignin; TP, total phenol; TT, total tannin; CT, condensed tannin; HT, hydrolysable tannin .

$* \mathrm{p}<0.05 ; * * \mathrm{p}<0.01 ; * * * \mathrm{p}<0.001$

and $\mathrm{CP}$

\section{DISCUSSION}

The nutrient compositions of studied browse were comparable with a range of values reported for Southern African species (Tefera et al., 2008) and tropical browses reported by various researchers (Soliva et al., 2008) in similar season. However, there were slight deviation for some of the species and this may be due to variation in site and within species variation. The means of secondary plant compounds obtained in this study were within the ranges of values reported for other tropical browses (Mueller-Harvey, 2006); but there was little information on the plant secondary compounds of most of browse under this study to

Table 10. Correlation coefficients (r) between chemical composition and phenolic compounds and methane production parameters of studied browse plants

\begin{tabular}{llc}
\hline Predictor & $\begin{array}{c}\text { Methane } \\
24 \mathrm{~h}\end{array}$ & $\begin{array}{c}\text { Methane increment in } \\
\text { absence of tannin }\end{array}$ \\
\hline Chemical composition & & -0.221 \\
CP & $0.36 *$ & $-0.653 * * *$ \\
NDF & $0.453 * * *$ & $-0.449 * *$ \\
ADF & $0.845 * * *$ & $-0.299 *$ \\
ADL & $0.426 * *$ & \\
Secondary compounds & & $0.808 * * *$ \\
TP & $-0.827 * * *$ & $0.725 * * *$ \\
TT & $-0.774 * * *$ & $0.617 * * *$ \\
CT & $-0.685 * * *$ & $0.604 * * *$ \\
HT & $-0.631 * * *$ & \\
\hline
\end{tabular}

$\mathrm{CP}$, crude protein; NDF, neutral detergent fiber; ADF, acid detergent lignin; ADL, acid detergent lignin; TP, total phenol; TT, total tannin; CT, condensed tannin; HT, hydrolysable tannin

$* \mathrm{p}<0.05 ; * * \mathrm{p}<0.01 ; * * * \mathrm{p}<0.001$. compare. In addition, there were large variations within most report even for the same species mainly due to assay method and differences in ecotypes, seasons, ecological zone, soil type, age of the plants (Mueller-Harvey, 2006).

Feed fermentation and digestibility determine nutritive values of browse and these two are further influenced by chemical and phenolic compositions. A high GP indicates greater fermentation to support rapid rumen microbial growth. In current study the main factors affecting GP and IVOMD of browse were their ADL and tannin contents. These differences could be due to the difference in chemical structure of cell walls (Tiemann et al., 2008) and the molecular weight of tannins (Patra and Saxena, 2009). In the present study tannin showed depressing effect in fermentability and digestibility of browses. Morus alba was the most fermentable and digestible browse that could be associated to the low ADF, ADL, and phenolic compounds. On the other hand Rhus lancea was the least fermentable and digestible browse that could be due to the negative influence of high TT and phenolic compounds irrespective of ADL composition. Moreover, for some species like Acacia nilotica; however, the effect of ADL and tannin contents cannot be separated. In agreement with current finding, studies done on different tropical browses had showed negative effects of plant phenolic compounds on their fermentation and digestion (Guglielmelli et al., 2011; Jayanegara et al., 2011; Sebata et al., 2011). The negative effect of tannins on fermentation and digestion could be related to the formation of tannin-carbohydrate and tanninprotein complexes that are less degradable or to toxicity to rumen microbes (Bhatta et al., 2009).

The high PD and b for Morus alba could be linked to high volume gas produced and their low fiber concentrations, since the PD and $\mathrm{b}$ were found to be 
negatively correlated with fiber components. The relative slow rate of GP (c) from high tannin containing browses might be due to the presence of high levels of plant secondary compounds, which are known to be toxic to rumen bacteria (Bhatta et al., 2009).

Some studies found that lower concentration of tannin (20 g/kg DM) had little or no impact on GP and total VFA concentration (Getachew et al., 2008). However, in current study the lower concentration of tannin (Melia azedarach, Ficus thronniggi, Olea europaea, and Olea africanum) had significantly influenced fermentation and digestibility. The decrease in fermentation and digestibility with increasing levels of tannin might be due to their continuous effect during fermentation and digestibility. Tan et al. (2011) had reported similar effects with increasing tannin level supplementation.

The increase in ammonia and short chain fatty acids with the absence of tannin during incubation period indicated that the depression of fermentation and digestion of organic matter by tannin content. In this study this was also be justified by the increased IVOMD with inclusion of PEG. The effect of tannin on ammonia production might be due to the formation of tannin-protein complexes that could reduce degradation of protein to ammonia (Bhatta et al., 2009). This finding is consistent with other researchers (Mueller-Harvey, 2006; Patra and Sexena, 2011). The absence of tannin had resulted in a substantial increase in total and individual VFA production. This finding was consistent with the finding of other researchers (Getachew et al., 2008; Singh et al., 2012). There is general agreement that dietary tannins supplied at adequate concentrations reduce ruminal ammonia and branched-chain VFA concentrations in vitro (Bhatta et al., 2009; Getachew et al., 2008; Singh et al., 2012) and in vivo (Getachew et al., 2008). This is because $\mathrm{NH}_{3}$ is a product of amino acid deamination, while iso-butyrate and iso-valerate are products of breakdown of the carbon skeleton of amino acids during rumen fermentation.

Enteric methane production primarily depends on the quantity and quality of the diet as it affects rate of ruminal digestion and passage (Beauchemin et al., 2008). Production of methane is a sink for hydrogen in the rumen during the process of utilization of feed energy. However, with fermentation of tannin rich plants, their bacteriocidal and bacteriostatic effects on the rumen microbes, and inactivation of their enzymes greatly suppresses fermentation and this could result in decrease of methane production. The highest volume of methane for Melia azedarach during early incubation and Ziziphus mucronata during latter incubations periods even in absence of tannin was due to low tannin content. In this study, browses with higher phenolic contents generally produced lower methane regardless of their $\mathrm{CP}, \mathrm{NDF}, \mathrm{ADF}$, and lignin contents.
When PEG was included in browse samples methane production increased which might be due to increased digestion and acetate shift VFAs production. For instance in current study for some of the browses (Peltrophorum africanum, Ziziphus mucronta, Ficus thronniggi, Morus alba, Ficus religiosa, Combretum microphyllum, Quercus rubica, and Acacia sieberriana woodii) PEG inclusion was resulted in decreased acetate to propionate ratio (data not showed), though that was not resulted in decreased in methane production. While for the other species (with PEG) the acetate shifted fermentation has resulted in increased methane production. Considering increased ratio of $\mathrm{CH}_{4}$ : VFA when tannin was bounded for all browses, it is clear that tannins had suppressed methane production irrespective of digestion and pattern of VFA production. The fact that the impact of the tannins on rumen methanogens was more pronounced than their effect on substrate degradation was also reported by Hassanat and Benchaar (2013). The decrease in methane production with inclusion of tannin in ruminant diet was similarly reported by several researchers (Bhatta et al., 2009; Sebata and Ndlovu, 2011; Singh et al., 2012). Jayanegara et al. (2011) conducted a meta-analysis and concluded that increasing tannin concentrations consistently suppressed $\mathrm{CH}_{4}$ production under in vitro and in vivo condition. The impact of tannins on methane production varies with tannin chemical structure (plant origin) as well as its concentration. It acted as toxicant to methanogens, reduced acetate and butyrate production (i.e. reduced fibre degradation) or a decline in OM digestion (Beauchemin et al., 2008; Patra and Sexena, 2011). Unlike Krueger et al. (2010) who reported low tannins (HT) has no or little impact on acetate, propionate or butyrate proportions, this study revealed a significant effect of tannin on these parameters.

The observed difference in methanogenic property within Olea europaea species and large variation among studied browse offers the opportunity to select species with low methanogenic potential when fed to ruminants. Variation within and amongst browses in metanogenic property has also been reported by other researchers (Soliva et al., 2008). Another interesting property of these tanniferous browse is, most of them are medicinal plants and that may attributed to their presumed antimicrobial properties. This property is desirable to reduce the efficiency of microbial protein synthesis by predation of bacteria and digestion of large amounts of ruminal bacteria. Hence the reduction in protozoal counts was often found to be associated with a lower methanogenesis (Bhatta et al., 2009).

\section{CONCLUSION}

Most of experimental plants tested in the present study 
generally contained more than $170 \mathrm{~g} / \mathrm{kg}$ of CP. Using them as supplements to low-CP tropical diets still would increase digestibility and reduce methane that could be generated from low quality roughage alone. It is also observed that if highly fermentable and digestible browses like Morus alaba and Melia azederech with comparatively lower tannins can be included in roughages diets they can increase fermentation and digestibility, reduce methane production. They might also provide ruminal ammonia necessary for maximal microbial protein production. However, a systematic evaluation is needed to determine optimum levels of supplementation in a mixed diet in order to attain a maximal depressing effect on enteric $\mathrm{CH}_{4}$ production with a minimal detrimental effect on rumen fermentation of poor quality roughage based diet.

\section{ACKNOWLEDGMENTS}

The research leading to these results has received funding from the European Community's Framework Programme (FP7/2007-2013) under the grant agreement no 266018ANIMALCHANGE. The authors are also grateful for co-funding grant from South Africa Department of Science and Technology and University of Pretoria for bursary award. Mr Jason Sampson and Ms Susan Myburgh from Botany garden, Department of Plant Science University of Pretoria have identified the plants in the field and assisted during sample collection and they deserve our special acknowledgement.

\section{REFERENCES}

Animut, G., R. Puchala, A. L. Goetsch, A. K. Patra, T. Sahlu, V. H. Varel, and J. Wells. 2008. Methane emission by goats consuming different sources of condensed tannins. Anim. Feed. Sci. Technol. 144:228-241.

AOAC. 2002. Official Methods of Analysis, 17th eds. Association of Official Analytical Chemists Inc. Arlington, VA, USA.

Beauchemin, K. A., M. Kreuzer, F. O. Mara, and T. A. McAllister. 2008. Nutritional management for enteric methane abatement: A review. Aust. J. Exp. Agric. 48:21-27.

Bhatta, R., Y. Uyeno, K. Tajima, A. Takenaka, Y. Yabumoto, I. Nonaka, O. Enishi, and M. Kurihara. 2009. Difference in the nature of tannins on in vitro ruminal methane and volatile fatty acid production and on methanogenic archaea and protozoal populations. J. Dairy Sci. 92:5512-5522.

Engels, E. and F. J. Van der Merwe. 1967. Application of an in vitro technique to South African forages with special reference to the effect to certain factors on the results. South African J. Agric. Sci. 10:983-992.

Getachew, G., W. Pittroff, D. H. Putnam, A. Dandekar, S. Goyal, and E. J. DePeters. 2008. The influence of addition of gallic acid, tannic acid, or quebracho tannins to alfalfa hay on in vitro rumen fermentation and microbial protein synthesis. Anim. Feed. Sci. Technol. 140:444-461.
Goering, H. K. and P. J. Van Soest. 1970. Forage fiber analyses (Apparatus, reagents, procedures, and some applications). USDA Agricultural Handbook No. 379, Pg. 1-20. ARSUSDA: Washington, DC, USA.

Guglielmelli, A., S. Calabro, R. Primi, F. Carone, M. I. Cutrignelli, R. Tudisco, G. Piccolo, B. Ronchi, and P. P. Danieli. 2011. In vitro fermentation patterns and methane production of sainfoin (Onobrychis viciifolia Scop.) hay with different condensed tannin contents. Grass Forage Sci. 66:488-500.

Grant, R.J. and D. R. Mertens. 1992. Impact of in vitro fermentation techniques upon kinetics of fiber digestion. J. Dairy Sci. 75:1263-1272.

Hassanat, F. and C. Benchaar. 2013. Assessment of the effect of condensed (acacia and quebracho) and hydrolysable (chestnut and valonea) tannins on rumen fermentation and methane production in vitro. J. Sci. Food Agric. 93:332-339.

Hristov, A. N., C. Oh, J Lee, R. Meinen, F. Montes, T. Ott, J. Firkins, A. Rotz, C. Dell, A. Adesogan, W. Yang, J. Tricarico, E. Kebreab, G. Waghorn, J. Dijkstra, and S. Oosting. 2013. Mitigation of greenhouse gas emissions in livestock production - A review of technical options for non- $\mathrm{CO}_{2}$ emissions. FAO Animal Production and Health Paper No. 177 (Ed. P. J. Gerber, B. Henderson, and H. P. S. Makkar). FAO, Rome, Italy.

Jayanegara, A., E. Winac, C. R. Solivaa, S. Marquardta, M. Kreuzera, and F. Leibera. 2011. Dependence of forage quality and methanogenic potential of tropical plants on their phenolic fractions as determined by principal component analysis. Anim. Feed. Sci. Technol. 163:231-243.

Krueger, W. K., H. Gutierrez-Ba nuelos, G. E. Carstens, B. R. Min, W. E. Pinchak, R. R. Gomez, R. C. Anderson, N. A. Krueger, and T. D. A. Forbes. 2010. Effects of dietary tannin source on performance, feed efficiency, ruminal fermentation, and carcass and non-carcass traits in steers fed a high-grain diet. Anim. Feed. Sci. Technol. 159:1-9.

Leng, R. A. 2008. The potential of feeding nitrate to reduce enteric methane production in ruminants. A Report to the Department of Climate Change Commonwealth Government of Australia. ACT Canberra Australia. http://www.penambulbooks.com/ Downloads/Leng-Final\%20Modified\%20\%2017-9-2008.pdf Accessed May 6, 2014.

Makkar, H. P. S. 2003. Quantification of Tannins in Tree and Shrub Foliage. A Laboratory Manual. Kluwer Academic Publishers, Dordrecht, the Netherlands.

McDonald, P., A. C. Stirling, A. R. Henderson, W. A. Dewar, G. H. Stark, W. G. Davie, H. T. Macpherson, A. M. Reid, and J. Salter. 1960. Studies on Ensilage. Technical Bulletin no. 24. Edinburgh School of Agriculture, Edinburgh, Scotland, UK. pp. 1-83.

Menke, K. H. and H. Steingass. 1988. Estimation of the energetic feed value obtained from chemical analysis and in vitro gas production using rumen fluid. Animal Research and Development 28:7-55.

Mueller-Harvey, I. 2006. Unraveling the conundrum of tannins in animal nutrition and health. J. Sci. Food Agric. 86:2010-2037.

Ørskov, E. R. and I. McDonald. 1979. The estimation of protein degradability in the rumen from incubation measurements weighted according to rate of passage. J. Agric. Sci. 92:499503. 
Ottenstein, D. M. and D. A. Bartley. 1971. Separation of free acids C2-C5 in dilute aqueous solution column technology. J. Chromatogr. Sci. 9:673-681.

Patra, A. K. and J. Saxena. 2011. Exploitation of dietary tannins to improve rumen metabolism and ruminant nutrition. J. Sci. Food Agric. 91:24-37.

Porter, L. J., L. N. Hrstich, and B. G. Chan. 1985. The conversion of procyanidins and prodelphinidins to cyanidin and delphinidin. Photochemistry 25:223-230.

Santoso, B., B. Mwenya, C. Sar, and J. akahashi. 2007. Methane production and energy partition in sheep fed timothy hay silage- or hay-based diets. Indonesian J. Anim. Sci. Vet. 12:2733.

SAS. 2004. SAS version 9.0. SAS Institute Inc., Cary, NC,USA.

Sebata, A., L. R. Ndlovu, and J. S. Dube. 2011. Chemical composition, in vitro dry matter digestibility and in vitro gas production of five woody species browsed by Matebele goats (Capra hircus L.) in a semi-arid savanna, Zimbabwe. Anim. Feed. Sci. Technol. 170:122-125.

Singh, B., A. Sahoo, R. Sharma, and T. K. Bhat. 2005. Effect of polethylene glycol on gas production parameters and nitrogen disappearance of some tree forages. Anim. Feed Sci. Technol. 123-124:351-364.

Soliva, C. R., A. B. Zeleke, C. Clement, H. D. Hess, V. Fievez, and M. Kreuzer. 2008. In vitro screening of various tropical foliages, seeds, fruits and medicinal plants for low methane and high ammonia generating potentials in the rumen. Anim. Feed. Sci. Technol. 147:53-71.
Tan, H. Y., C. C. Sieo, N. Abdullah, J. B. Liang, X. D. Huang, and Y. W. Ho. 2011. Effects of condensed tannins from Leucaena on methane production, rumen fermentation and populations of methanogens and protozoa in vitro. Anim. Feed. Sci. Technol. 169:185-193.

Tavendale, M. H., L. P. Meagher, D. Pacheco, N. Walker, G. T. Attwood, and S. Sivakumaran. 2005. Methane production from in vitro rumen incubations with Lotus pedunculatus and Medicago sativa, and effects of extractable condensed tannin fractions on methanogenesis. Anim. Feed Sci. Technol. 123124:403-419.

Tefera, S., V. Mlambo, B. J. Dlamini, A. M. Dlamini, K. D. N. Koralagama, and F. L. Mould. 2008. Chemical composition and in vitro ruminal fermentation of common tree forages in the semi-arid rangelands of Swaziland. Anim. Feed Sci. Technol. 142:99-110.

Theodorou, M. K., B. A. Williams, M. S. Dhanoa, A. B. McAllen, and J. France. 1994. A simple gas production method using pressure transducers to determine the fermentation kinetics of ruminant feed. Anim. Feed Sci. Technol. 48:185-197.

Tiemann, T. T., P. Avila, G. Ramírez, C. Lascano, M. Kreuzer, and H. D. Hess. 2008. In vitro ruminal fermentation of tanniniferous tropical plants: Plant-specific tannin effects and counteracting efficiency of PEG. Anim. Feed Sci. Technol. 146:222-241

Tilley, J. M. A. and R. A. Terry. 1963. A two-stage technique for the in vitro digestion of forage crops. Grass Forage Sci.18:104111 .

Van Soest, P. J., J. B. Robertson, and B. A. Lewis. 1991. Methods for dietary fiber, neutral detergent fiber, and nonstarch polysaccharides in relation to animal nutrition. J. Dairy Sci. 74:3583-3597. 